\title{
Graphical content of medicinal package inserts: an exploratory study to evaluate potential legibility \\ issues
}

Carla Pires*, Marina Vigário ${ }^{\dagger} \&$ Afonso Cavaco*

* Research Institute for Medicines and Pharmaceutical Sciences, Faculty of Pharmacy, University of Lisbon, Lisbon, Portugal, and ${ }^{\dagger}$ Centre of Linguistics of the University of Lisbon, School of Arts and Humanities, University of Lisbon, Lisbon, Portugal

\begin{abstract}
Background: The graphical content of the Medicines Package Inserts (MPIs), such as illustrations and typographic features should be legible and appropriate, as required by international pharmaceutical regulations.

Objectives: To study: (1) the frequency and type of MPIs' key graphic elements, (2) their compliance with regulations and (3) how educated people understand them.

Methods: Descriptive study: characterisation of the graphical content of 651 MPIs. Usability study: illustrations and tables (purposively selected) were evaluated with questionnaires in three groups of humanities undergraduates (illustrations only, illustrations plus text and text only).

Results: Descriptive study: illustrations and tables were respectively identified in $6.3 \%$ and $11.8 \%$ of the MPIs. The illustrations were mainly related to how to take/use the medicine. Non-recommended graphical representations were found (e.g. italic or underline). Usability test: legibility issues were identified, especially for the group of isolated illustrations.

Discussion \& conclusions: The scarce use of illustrations and tables possibly affected the legibility of the MPIs. Compulsory legibility tests are needed to guarantee the MPIs' proper use, thus contributing to a safe use of medicines. Overall, this study highlighted the need to carefully revise/assess the MPIs' design and probably increase health information experts' awareness on this issue.
\end{abstract}

Keywords: communication, consumer health information; health information needs; patient information

Key messages

- Although the use of illustrations supports patients' comprehension, satisfaction, adherence and recall, they were scarcely used in a large sample of Portuguese package inserts.

- Usability issues were found concerning the illustrations and tables of medicinal package inserts an educated people, which suggest greater problems for the low-literate groups.

- This study raises the question of the relevance of the quality assessment and legibility assurance of the medicinal packages inserts.

- It is advisable to update the regulations on the use of graphic elements and to develop methods for approving legibility of package inserts.

- Specialists in health information and related areas are likely to contribute to the improvement of the graphic content and readability of the package inserts.

\section{Introduction}

Users' awareness of health information materials and their reaction patterns, such as satisfaction,

*Correspondence: Carla Maria Pires, Research Institute for Medicines and Pharmaceutical Sciences, Faculty of Pharmacy, University of Lisbon, Av. Prof. Gama Pinto, 1649-003 Lisboa, Portugal. E-mail: cmbpires@ff.ul.pt reassurance or worry, as well as their ability to use this information (i.e. self-efficacy) vary not only between individuals but also when the readability and design characteristics of these materials are concerned. ${ }^{1-6}$ This is specifically relevant for the low-literate patients, since those with limited comprehension of health materials are more likely 
to experience poor health related outcomes, including fatalities. ${ }^{4-7}$

Health information materials and, particularly, Medicines Package Inserts (MPIs) are very relevant for consumers, patients and health professionals as a way of transmitting safety and efficacy information about medicines. ${ }^{8-10}$ In a study by Hamrosi at al. (carried out in 2009), a national sample of Australian consumers, community pharmacists and general practitioners were questioned about their preferences on sources of medicine information. The findings of this study revealed that, $68 \%$ of the consumers, $34 \%$ of the pharmacists and $23 \%$ of the general practitioner preferred the MPIs as sources of medicine information. In this study, the favourite information sources for the pharmacists and general practitioners, respectively, were the consumer medicine information and the oral information. ${ }^{6}$

MPIs are available inside all the packages of medicinal products in the European Union member states, ${ }^{9}$ and must be designed and tested according to the requirements of the Guideline on the Readability of the Labelling and Package Leaflet. $^{10}$ In accordance to this guideline and current scientific literature, MPIs need to be clearly understood in an appropriate timeframe by patients, including illustrations and tables. ${ }^{10-14}$

Illustrations and symbols are specifically allowed to be used in MPIs by medicines agencies, such as the European Medicine Agency (EMA, Europe), the Food and Drug Administration (FDA, United States of America) and the Therapeutic Goods Administration (TGA, Australia). ${ }^{10,15,16}$ Illustrations should reflect the information accurately and unambiguously, and should not be suggestive of non-approved indications. $^{10,11,16}$ In addition, the medicines regulatory authorities also established some design and layout recommendations for the MPIs, ${ }^{9,17}$ such as text orientation (portrait), bullet points (left alignment), titles (centered, bold, capital letters), heading (bold, capital letters), subheadings (bold, normal letters), tables (single line style). ${ }^{17}$

Besides the above mentioned regulatory requirements, there are scientific studies specifically done on the positive and negative aspects of using illustrations ${ }^{18-22}$ or other graphic elements in the MPIs and other written documents (e.g. bullets or headings). ${ }^{20,23-27}$ Illustrations increase attention, comprehension and recall of health materials, this being particularly relevant for the low-literate patients, ${ }^{4,5}$ and especially if pictures are associated with written text or oral instructions. ${ }^{11,14,18,20,28,29}$ For instance, in the US Sojourner et al. ${ }^{20}$ used three groups of participants (undergraduates, younger adults and elders) to evaluate their satisfaction and recall of written information in three forms (text only, pictures only or text with pictures); overall, the text with pictures was better rated and recalled. On the other hand, caution is recommended when using illustrations in MPIs because, in certain cases, illustrations are not helpful or appropriate. ${ }^{11,21,30,31}$ For instance, in a study to evaluate common warning proprieties, Webb et $a .^{21}$ found that in the majority of the cases pictures were confusing for the participating patients from a general internal medicine clinic in United States, with around half of them presenting limited literacy. Moreover, the use of bold, bullets and headings are among the common design strategies to facilitate the reading of prose information. $^{17,23,24,27,33}$ Oppositely, the use of underline, italics, hyphenated lists, headings with text boxes and capitalised letters in the body text are not recommended (e.g. the use of capitalised sentences in the body text), because these items do not favour text legibility. 17,23,24,27,33 For instance, boxed headings must not appear in the final printed packaging materials. $^{17}$

Given the current regulatory requirements and the existing body of literature, ${ }^{1-33}$ it was considered relevant to characterise the graphic elements in a representative sample of Portuguese MPIs, as well as to evaluate the level of potential users' comprehension regarding illustrations and tables from the sampled MPIs. In this context, two exploratory studies were developed (Study A and B): Study A aimed to a) characterise (quantitatively and qualitatively) all the following key graphical elements, i.e. figures, pictograms, tables and other graphical elements (OGE), such as bold or bullet points in a representative sample of Portuguese MPIs, and b) assess the compliance of these graphical elements with pharmaceutical regulations; and Study B (a usability test) aimed to assess the comprehension of purposively selected illustrations and tables within a group of non health care educated people. 


\section{Methods}

Study A - The descriptive study

A cross-sectional study design was followed: all the MPIs of branded medicines included in the National Prescribing Guide and also from the three therapeutic groups of medicines most consumed in Portugal (2009 health market data), i.e. cardiovascular (CS), central nervous (CNS) and musculoskeletal systems (MS) were selected. ${ }^{34,35}$ The MPIs of the generic medicines were not selected because these MPIs are very similar or even equal to the MPIs of branded medicines. ${ }^{9,36}$ The MPIs were identified in a public medicine database (Infomed) between January and March 2012. ${ }^{37}$

For this study, it was defined that pictograms were illustrations composed of at least two images, figures were illustrations composed of only one image, ${ }^{38}$ tables were graphic representations with rows and columns, and the lists or iterations were groups of words or sentences preceded by hyphens, bullet points or other graphic elements. In addition, other graphic elements (OGE) were also identified and quantified in the sampled MPIs. The studied OGE were: bold font, italics, underline, capitalised letters in the body text (the titles and sub-tittles were not evaluated, i.e. only the existence of uppercase in the body text was registered), headings with text boxes, associations of the previous graphic elements, other graphic elements used to highlight information (e.g. symbols, such as an arrow to highlight important facts at the end of the sections), and the case format of the section titles (uppercase, lowercase or both). The data collection was based on the application of a checklist (Appendix A), which facilitated the identification and quantification of figures, pictograms, tables, lists/iterations and OGE in the sampled MPIs.

The occurrence of figures, pictograms, tables, lists/iterations and OGE (Appendix A: checklist) was also quantified in each one of the 6 sections of the MPI: 1) What is $X$ and what is used for ( $X=$ medicinal product name), 2) What you need to know before you <take $\rangle\langle$ use $>X$, 3) How to $<$ take> <use> X, 4) Possible side effects; 5) How to store $X$ and 6) Contents of the package and other information, as stated in the Quality Review of Documents (QRD) template. ${ }^{32,39}$ The QRD template is used by applicants and marketingauthorisation holders to standardise the information of MPIs, as in the case of the medicines with a single marketing authorisation valid in all countries of the European Union (medicines approved via a centralised authorisation procedure by the EMA). ${ }^{40}$ In the case of these medicines, a translated version of the same MPI is used in all European countries. ${ }^{32,39,40}$

Qualitative descriptors were defined to classify the content of the illustrations and the topics associated with the use of graphic elements. The checklist and the qualitative descriptors (Table 1) were developed considering the Portuguese and European regulations $\mathrm{s}^{9,10,17,32,33,36}$ and, in particular, the terminology of the QRD template (version 8). ${ }^{32}$

The study data were submitted to a quality control procedure according to the principles of the NBR 5425 norm. ${ }^{41}$ First, all variables of the study were collected in an MS Excel database and, second, around $15 \%$ of the MPIs were randomly selected and re-analysed to confirm data consistency. This procedure was performed by a single researcher.

\section{Study B - The usability study}

A cross-over study design was used: three independent self-administered questionnaires (Appendix B) were used to assess participants' comprehension of two figures, two pictograms and two tables. These illustrations and tables were purposively selected from the sampled MPIs based on the criteria of previous studies, ${ }^{11,18,20,28,29,42}$ and after the consensus cycles within the research team. The initial inclusion criteria was based on the selection of all illustrations and tables related to how to take/use the medicine, because in accordance to previous studies, this theme is relevant for patients, potential users of medicines and health professionals. ${ }^{18,25,43}$ In a second step, the following illustrations were purposively selected: two figures on the administration of tablets (instructions to not break a tablet or on how to split a pill), because tablets are the most commonly consumed pharmaceutical forms, ${ }^{35}$ and two pictograms covering other types of 
Table 1 Qualitative descriptors of the graphic elements

\begin{tabular}{|c|c|c|c|c|}
\hline & & \multicolumn{3}{|c|}{ Therapeutic groups } \\
\hline \multicolumn{2}{|c|}{ Classification } & $\begin{array}{l}\text { CNS (309 MPIs) } \\
n(\%)^{*}\end{array}$ & $\begin{array}{l}\text { CS (179 MPIs) } \\
n(\%)^{*}\end{array}$ & $\begin{array}{l}\text { MS (163 MPIs) } \\
n(\%)^{*}\end{array}$ \\
\hline \multirow[t]{5}{*}{1.} & Qualitative descriptors of the Figures: & & & \\
\hline & How to $<$ take $><$ use $>$ & $7(100)$ & $2(100)$ & $3(33.3)$ \\
\hline & How it looks like & $0(0)$ & $0(0)$ & $3(33.3)$ \\
\hline & Precautions & $0(0)$ & $0(0)$ & $3(33.3)$ \\
\hline & Total of figures & $7(100)$ & $2(100)$ & $9(100)$ \\
\hline \multirow[t]{3}{*}{2.} & Qualitative descriptors of the Pictograms: & & & \\
\hline & How to $<$ take $><$ use $>$ & $17(100)$ & $2(100)$ & $4(100)$ \\
\hline & Total of pictograms & $17(100)$ & $2(100)$ & $4(100)$ \\
\hline \multirow[t]{9}{*}{3.} & Qualitative descriptors of the Tables: & & & \\
\hline & ADR (description + frequency) & $4(9.8)$ & $8(42)$ & $2(11.8)$ \\
\hline & ADR frequency & $5(12.2)$ & $2(10.5)$ & $4(23.5)$ \\
\hline & Precautions & $1(2.4)$ & $0(0)$ & $0(0)$ \\
\hline & Interactions & $1(2.4)$ & $1(5.3)$ & $0(0)$ \\
\hline & Posology & $19(46.3)$ & $4(21)$ & $10(58.8)$ \\
\hline & Fargerström Test & $2(4.9)$ & $0(0)$ & $0(0)$ \\
\hline & Marketing Authorisation Holders & $9(22)$ & $4(21.1)$ & $1(5.9)$ \\
\hline & Total of tables & $41(100)$ & $19(100)$ & $17(100)$ \\
\hline \multirow[t]{20}{*}{4.} & Qualitative descriptors of all Lists/Iterations: & & & \\
\hline & What is used for & $54(5.1)$ & $51(7.8)$ & $65(12.6)$ \\
\hline & Mechanism of action & $0(0)$ & $6(0.9)$ & $2(0.4)$ \\
\hline & Do not use & $234(22.2)$ & $147(22.5)$ & $128(24.8)$ \\
\hline & Take special care & $187(17.7)$ & $107(16.4)$ & $87(16.7)$ \\
\hline & Interactions & $130(12.3)$ & $77(11.8)$ & $51(9.9)$ \\
\hline & Pregnancy & $19(1.8)$ & $7(1.1)$ & $7(1.4)$ \\
\hline & Breast feeding & $7(0.7)$ & $8(1.2)$ & $4(0.8)$ \\
\hline & Fertility & $0(0)$ & $0(0)$ & $1(0.2)$ \\
\hline & Driving & $2(0.2)$ & $2(0.3)$ & $1(0.2)$ \\
\hline & Posology & $63(6)$ & $29(4.4)$ & $19(3.6)$ \\
\hline & Overdose & $31(2.9)$ & $4(0.6)$ & $5(1)$ \\
\hline & Routine examinations & $4(0.4)$ & $2(0.3)$ & $4(0.8)$ \\
\hline & Administration form & $22(2.1)$ & $19(2.9)$ & $10(1.9)$ \\
\hline & ADR & $122(11.6)$ & $73(11.2)$ & $30(5.8)$ \\
\hline & Conservation & $10(0.9)$ & $15(2.3)$ & $4(0.8)$ \\
\hline & Packaging & $4(0.4)$ & $3(0.5)$ & $4(0.8)$ \\
\hline & Physical aspect & $6(0.6)$ & $4(0.6)$ & 0 \\
\hline & Composition & $159(15.1)$ & $100(15.2)$ & $95(18.3)$ \\
\hline & Total of Lists/Iterations & $1054(100)$ & $654(100)$ & $517(100)$ \\
\hline \multirow[t]{9}{*}{5.} & Qualitative descriptors of the OGE: & & & \\
\hline & Bold & $45(16.6)$ & $19(15.1)$ & $26(19)$ \\
\hline & Headings with text boxes ${ }^{\dagger}$ & $1(0.4)$ & $1(0.8)$ & 0 \\
\hline & Italic ${ }^{\dagger}$ & $26(9.6)$ & $11(8.7)$ & $12(8.8)$ \\
\hline & Capitalised letters in the body text $t^{\dagger+*}$ & $142(52.4)$ & $67(53.2)$ & $77(56.2)$ \\
\hline & Graphic elements associations (a mix of the previous) & 0 & $1(0.8)$ & $1(0.7)$ \\
\hline & Underline $^{\dagger}$ & $53(19.5)$ & $27(21.4)$ & $21(15.3)$ \\
\hline & $\begin{array}{l}\text { Use of one graphic element to highlight and/or } \\
\text { summarise key information }\end{array}$ & $4(1.5)$ & $0(0)$ & $0(0)$ \\
\hline & Total of OGE & $271(100)$ & $126(100)$ & $137(100)$ \\
\hline \multirow[t]{2}{*}{6.} & Format of letters in MPIs titles: & & & \\
\hline & All capital letters & $233(75.4)$ & $128(71.5)$ & $115(70.6)$ \\
\hline
\end{tabular}


Table 1. (continued)

\begin{tabular}{|c|c|c|c|}
\hline \multirow[b]{2}{*}{ Classification } & \multicolumn{3}{|c|}{ Therapeutic groups } \\
\hline & $\begin{array}{l}\text { CNS (309 MPIs) } \\
n(\%)^{*}\end{array}$ & $\begin{array}{l}\text { CS (179 MPIs) } \\
n(\%)^{*}\end{array}$ & $\begin{array}{l}\text { MS (163 MPIs) } \\
n(\%)^{*}\end{array}$ \\
\hline Capital letters only at the beginning ${ }^{\dagger}$ & $42(13.6)$ & $21(11.7)$ & $17(10.4)$ \\
\hline Mix of upper and lower case letters ${ }^{\dagger}$ & $34(11)$ & $30(16.8)$ & $31(19)$ \\
\hline Total of analysed headings ${ }^{\S}$ & $309(100)$ & $179(100)$ & $163(100)$ \\
\hline
\end{tabular}

MPIs, medicines package inserts; CNS, central nervous system; CS, cardiovascular system; MS, musculosketal system; $n$, number; OGE, other graphical elements; ADR, adverse drug reactions.

Precautions: The description of the safety measures on how to use the medicines (e.g. type of actions in case the patient suffer from a certain disease). ${ }^{32}$. ADR - Adverse drug reactions: A response to a medicinal product which is noxious and unintended; usually occurring at doses normally used in man. ${ }^{9}$. ADR frequency: The probability of occurring a certain ADR (e.g. 1 in 1000 individuals). ${ }^{32}$. Interactions: Description of the possible interactions between the medicine described in the MPI with other medicine(s) or other types of substance(s) (e.g. an enhanced or decreased effect of a drug). ${ }^{32}$. Posology: The quantity and frequency of administration of the medicine to have a therapeutic effect (dosage information). ${ }^{32}$. Fargerström Test: A test to evaluate the smoker's degree of dependence on nicotine. Marketing Authorization Holders: The marketing authorization holder (e.g. a company) is the responsible for all aspects of the product (e.g. the efficacy and safety of the medicine). ${ }^{9,36}$. Driving: The description of possible negative effects on the ability to drive and use machines and the required actions if any undesirable effect occur. ${ }^{32}$. Overdose: An hazard dose of a medicine - description of the type of symptoms and necessary actions. ${ }^{32}$

*The percentages were calculated in relation to the number of MPIs of each therapeutic group.

${ }^{+}$Graphic elements non-recommended in the pharmaceutical regulations. ${ }^{10,17,33}$

${ }^{\ddagger}$ The titles and sub-tittles were not evaluated in this assessment, i.e. only the existence of uppercase in the body text was registered.

§It was classified the first heading of all MPIs.

administration instructions: one pictogram on syrup administration of a prescription for paediatric medicines, because the caregivers of children manifest a preference for simple and clear written materials, ${ }^{3}$ and one pictogram on the transdermal system application of a OTC medicine, because OTC may be acquired without health professionals' mediation..$^{9,23,36}$ In addition, the tables with the highest number of columns and rows were selected, because these tables are likely to comprise more information and, thus are likely to be more complex to read and interpret. All evaluated illustrations and tables (two figures, two pictograms and two tables) are presented in Appendix B. In addition, open questions were used to evaluate participants' health knowledge, functioning also as an exclusion criteria. These questions were on: (1) participants' previous health training (trainers or trainees); (2) any work experience in the health sector, including caregiving and/or (3) any other situation susceptible of contributing to the increase in health knowledge. All the participants answered negatively to the previous questions, thus none was excluded. Demographic data were also collected (age, gender and years of study).

Study participants were conveniently recruited from undergraduate humanities courses, in April 2013. These participants were selected: (1) to avoid expertise bias, because no specific health knowledge is expected from them, for instance in comparison to the undergraduates of medicine, nursing or pharmacy; and also (2) to obtain an appropriate use of the information, ${ }^{4,5,8}$ because, it was considered that university students are more likely to have a higher literacy level than the general population. Furthermore, according to the last Portuguese Census (2011), around 70\% of the Portuguese population only have the 9th grade or less, ${ }^{44}$ and according to the last national health literacy study (2014), $61.4 \%$ of all the participants presented problematic or inadequate health literacy. ${ }^{45}$ In this context, it was assumed that if usability issues were found in this study, even worse results would possibly be expected from the general Portuguese population. 
Participants were randomly assigned to one of the three groups: Group 1 (only isolated illustrations were evaluated); Group 2 (the same illustrations used in Group 1 plus an excerpt of the text were evaluated) and Group 3 (only the excerpt of texts used in Group 2 without the illustrations were evaluated). This methodological design was defined to separately identify possible readability and legibility issues, respectively in the groups of isolated illustrations (figures or pictograms) (Group 1) or texts (Group 3), while confirming the greater intelligibility of text plus image association (Group 3). Furthermore, this methodology was already used in other studies. $^{11,18,20,28,29}$ In particular, the excerpts of text were specifically matched with the text of the MPIs about the illustrations given. Groups 1, 2 and 3 were respectively composed of 17, 14 and 14 participants. The sample sizes were conveniently defined based on previous studies on the same research topic. ${ }^{10,11,18,46}$

All the questionnaires were similar in their structure and used both open and closed questions (Appendix A). The open questions were used to collect participants' general interpretation of the illustrations and the tables selected, where the questions about the tables asked participants to consult the table and indicate the right dosage (expressed in $\mathrm{ml}$ ) of a paediatric syrup. The close questions were based on a Likert scale, used for rating the table layouts. All collected data were completely anonymous and confidential.

\section{Statistical analysis}

The statistical data analysis was performed using SPSS (IBM-SPSS version 19.0, Chicago, IL). Besides the general evaluations of the descriptive statistic (e.g. percentage, median, mode, etc.), the Kruskal-Wallis (K-W) test was used to perform comparisons between more than two groups. This test was used to evaluate the difference between the proportions of: (1) different graphic elements in the MPIs from the three therapeutic groups (CNS, CS and MS) (Study A) and (2) the participants' correct or incorrect interpretations on the evaluated illustrations between the three groups: illustrations only, illustrations plus text and text only (Study B). When applicable, the non-parametric test Mann-Whitney $U$-test, was also used, specifically for comparisons between the two groups. Non-parametric tests were selected, because most study variables were nominal, i.e. presence/absence of a certain graphical element in the sampled MPIs or the classification of correct/incorrect participants' replies and the data not followed a normal distribution, i.e. other type of statistical testing was limited. A significant level of $P<0.05$ was used for all statistics.

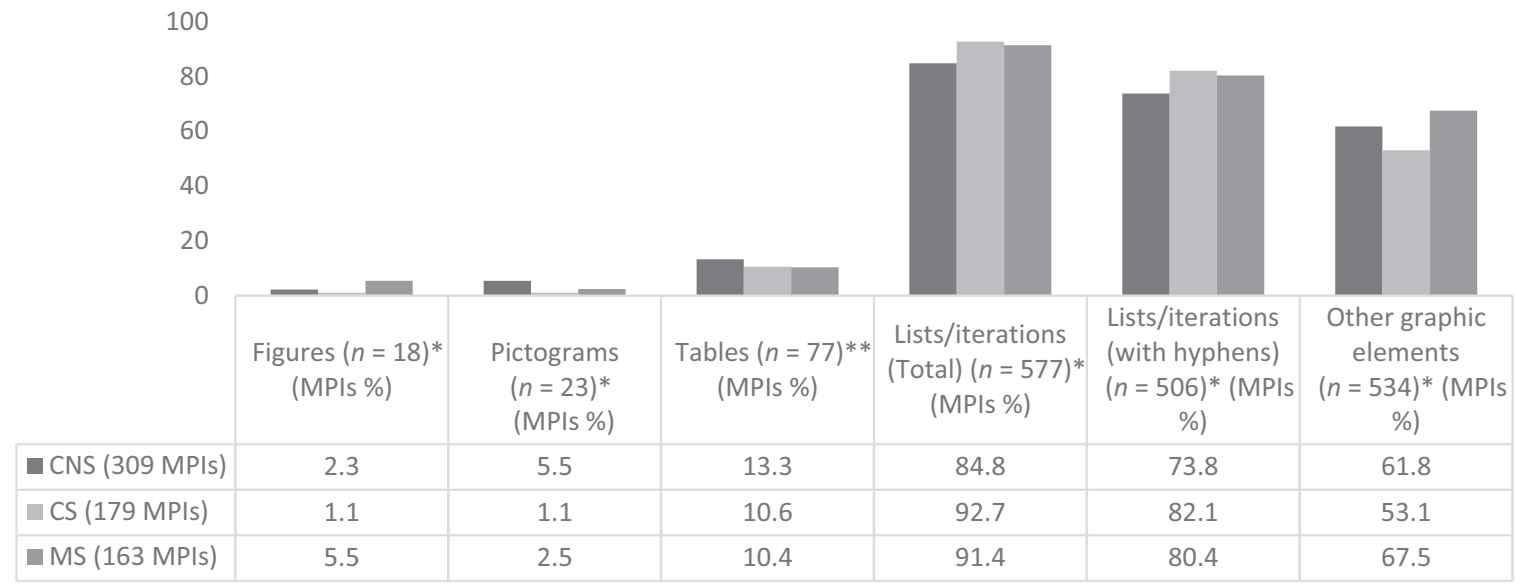

Figure 1 Percentage of package inserts containing different graphic elements. * The proportion of figures $(\mathrm{K}-\mathrm{W}=3.677$; $P=0.045)$, pictograms $(K-W=7.124 ; P=0.006)$, lists/iterations $(K-W=8.759 ; P=0.004)$ and OGE $(K-W=7.115$; $P=0.007)$ was significantly different between the MPIs of the three therapeutic groups (CNS, CS and MS). ** The proportion of tables $(\mathrm{K}-\mathrm{W}=0.670 ; P=0.391$ ) was not statistically different between the MPIs of the three therapeutic groups (CNS, CS and MS) 


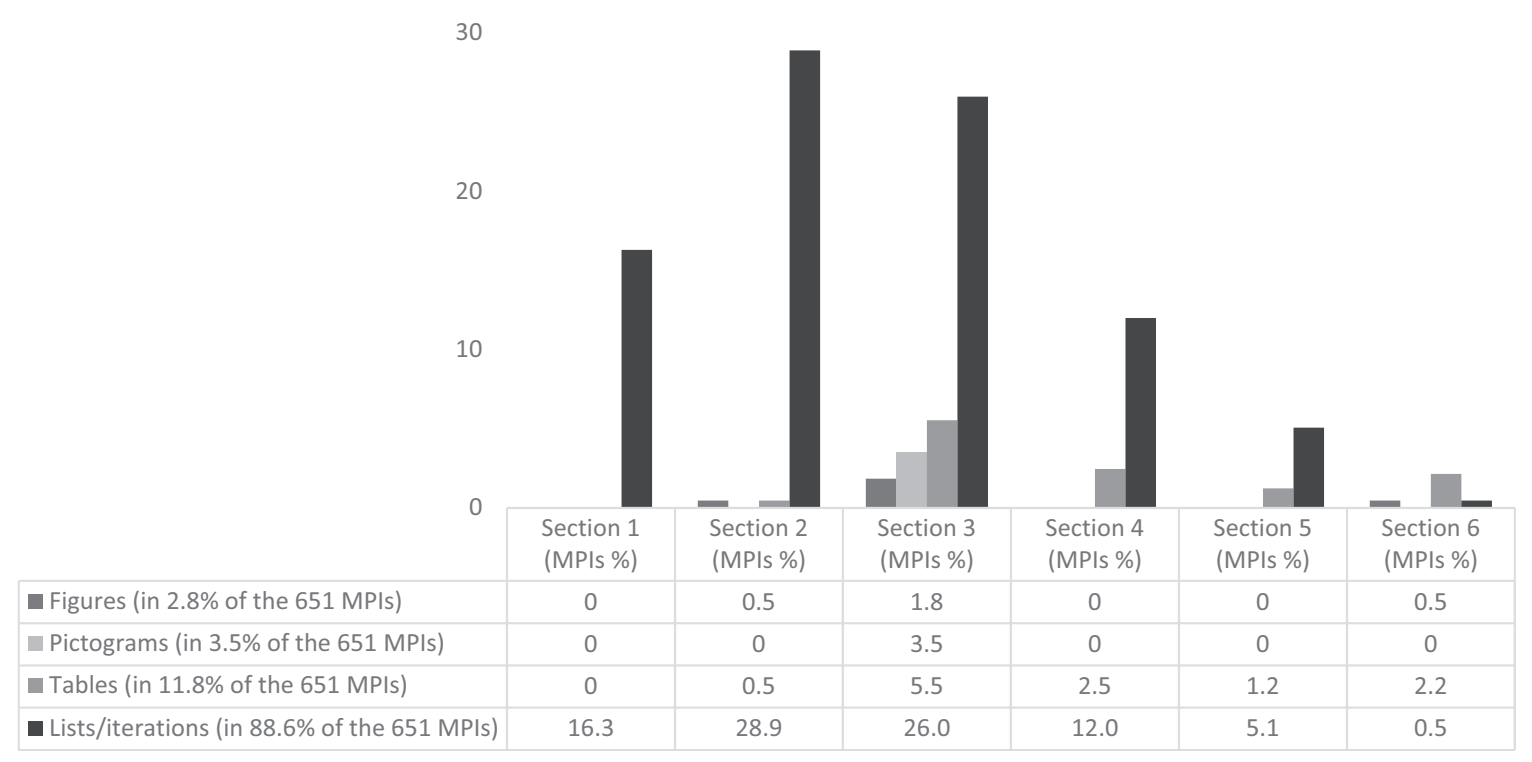

Figure 2 Percentage of package inserts containing illustrations, tables and lists/iterations (section 1 to 6)

\section{Results}

Study A - The descriptive study

A total of 651 MPIs were selected and analysed. The percentages of MPIs containing different graphic elements in each therapeutic group (CNS, CS, MS) are presented in the Fig. 1.

The qualitative descriptors of the graphic elements are presented in Table 1. The classification and distribution of the nonrecommended graphical elements, ${ }^{17,23,24,27,33}$ i.e. hyphenated lists (instead of bullet lists), headings with text boxes, italic, capitalised letters in the body text, underline and titles of sections not fully capitalised are presented in the Table 1 .

The percentage of MPIs containing illustrations, tables and lists/iterations in each one of the six sections of the MPIs $(n=651)$ is presented in Fig. 2. The description of the figures and pictograms of the sampled MPIs is presented in Table 2.

Overall, 18 figures and 23 pictograms were respectively identified in $2.8 \%$ and $3.5 \%$ of the 651 MPIs (Fig. 1). Only three MPIs included both figures and pictograms (buprenorphine, mirtazapine and valsartan) (Table 2). The figures were related to medicine taking/usage (e.g. transdermal patch application), their visual aspects (e.g. colour, shape and groove of tablets) and precautions (e.g. risk of bone fracture) (Table 1). The majority of figures were related to oral solid forms ${ }^{47}$ (e.g. tablets or capsules to be taken orally), and the rest to oral liquid forms, ${ }^{47}$ (e.g. syrups or suspensions to be taken orally) and to one case of a dermal spray. All the pictograms were related to taking/usage instructions and different routes of administration (e.g. injectable solution, transdermal patch, etc.) (Tables 1 and 3).

Seventy-seven tables were identified in $11.8 \%$ of the 651 MPIs. These tables were related to information on: (1) dosage, (2) adverse reactions frequency and (3) marketing authorisation holder (MAH) information (e.g. address) (Table 1).

Besides the low prevalence of figures, pictograms and tables in the sampled MPIs $(n=651)$, these graphic elements were predominantly used in the section 3 of the MPIs (i.e. How to $<$ take $><$ use $>X$ ) (Fig. 2). The lists/iterations were more predominantly used in the section 2 (i.e. What you need to know before you <take> <use>) and 3 (Fig. 2) in comparison to the other sections.

\section{Study B results: The usability study}

The participants' socio-demographic characteristics and the percentage of correct answers are presented in Table 3. All evaluated illustrations and tables are presented in Appendix B. 


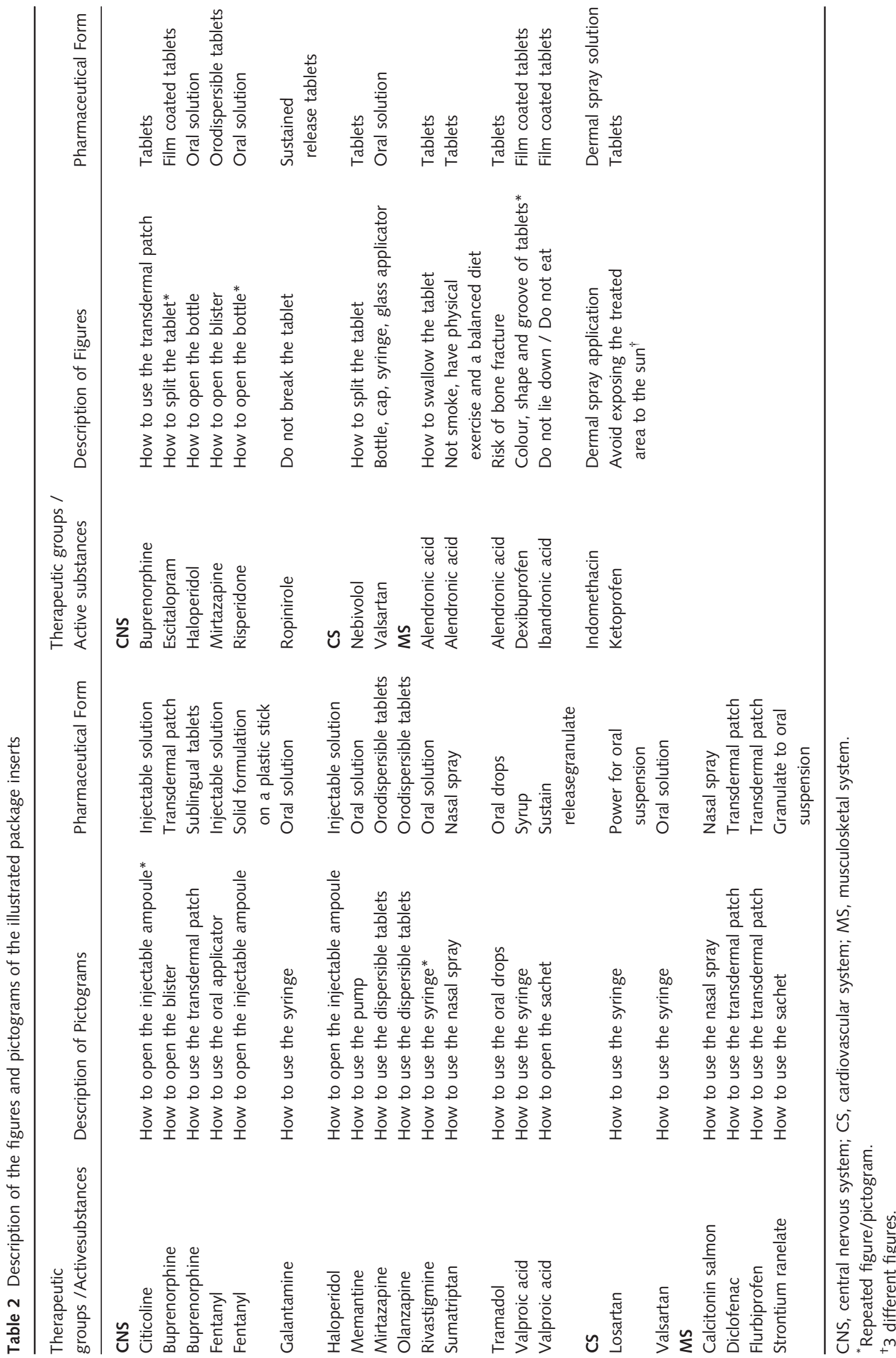


Table 3 Study B: demographic and interpretation results

\begin{tabular}{llll}
\hline & Group 1 Illustrations Only & Group 2 Illustrations + text & Group 3 Text only \\
\hline Demographic results & & 14 & 14 \\
Number of undergraduates & 17 & $23 \pm 3.7$ & $22.6 \pm 6.1$ \\
Age (mean \pm SD) & $22.5 \pm 3$ & 2 & 3 \\
Course year (median) & 3 & $7(50 \%)$ & $10(71.4 \%)$ \\
Gender (females) $n(\%)$ & $14(82.4 \%)$ & 100 & 100 \\
Correct answers (mean \pm SD) (\%) & $50 \pm 3$ & $89.3 \pm 3.6^{*}$ & $96.0 \pm 3.6^{*}$ \\
Figures & $84.3 \pm 16$ & & \\
Pictograms &
\end{tabular}

$\mathrm{SD}$, standard deviation; $n$, number.

*All the answers were fully correct, with the exception of one case of a blank answer.

According to the Kruskal-Wallis statistic results, the distribution of participants' age $(\mathrm{K}-\mathrm{W}=0.068$; $P=0.967)$, course year $(\mathrm{K}-\mathrm{W}=4.002 ; P=0.135)$ and $\operatorname{sex}(\mathrm{K}-\mathrm{W}=3.726 ; \quad P=0.155)$ were not significantly different between the groups, although there was a slightly higher proportion of females in the groups of isolated illustrations $(82.4 \%, n=14)$ and text $(71.4 \%, n=10)$ in comparison to the illustrations plus text group $(50 \%, n=7)$. On the contrary, the distribution of the participants' correct answers/interpretations for figures $(\mathrm{K}-\mathrm{W}=34.137$; $P<0.001)$ and for pictograms $(\mathrm{K}-\mathrm{W}=8.819$; $P=0.012) \quad$ was statistically different, with significantly worse interpretation issues for the groups of isolated illustrations. In addition, the answers between the group of isolated illustrations (figures only vs. pictograms only), were compared with significantly better interpretation of results for the group of the isolated pictograms $(U=2210$, $P<0.001)$.

Legibility problems were detected in the case of the isolated figures (Group 1), because participants' only adequately interpreted these isolated graphic elements in approximately half of the cases (average correct score $50 \pm 3 \%$ ) (Table 3). The qualitative analysis of participants' comprehension on these isolated figures (Group 1), confirmed that participants were not able to recognise the presence of a blister (Fig. 3 - do not break the tablet) or the slot in the middle of the tablet for easily splitting (Fig. 4 - how to split the tablet) (Appendix B). As opposed to this, the participants did not experience any interpretation problems concerning the figures associated with the text excerpts or concerning the texts alone
(Group 2 and 3): 100\% of correct interpretations in both cases were obtained. (Table 3).

Legibility problems were also identified in the case of isolated pictograms (correct score $84.3 \pm 16 \%$ ) (Group 1), although the score was not as low as with the isolated figures (Table 3). Considering as well the qualitative analysis of participants' comprehension on isolated pictograms (Group 1), in the case of the pictogram showing the method for syrup administration (Fig. 5) (Appendix B), almost all the participants mistook the bottle syringe adapter for the bottle cap (the second image in the pictogram). Approximately, one-third of the participants supposed the container was used for discarding the remaining syrup in the syringe or for washing the syringe with alcohol instead of water (the last image of the pictogram). Interestingly, a limited number of participants' comprehension issues were also found in the groups of pictograms plus text (Group 2) and text only (Group 3): respectively, $89.3 \pm 3.6 \%$ and $96.0 \pm 3.6$ correct scores (Table 3 ).

In addition, the task of consulting a table to indicate a specific dosage (in $\mathrm{mL}$ ) showed that all the participants indicated the correct dosage interval, but only two calculated the exact volume. Overall, the participants classified the tables as good in relation to their layout (Appendix B), without statistical differences between groups $(\mathrm{K}-\mathrm{W}=2.071 ; P=0.355)$.

\section{Discussion}

This study comprised two studies, a descriptive and a usability study. The descriptive study 
contributed to the increase in the interest in the use of graphic elements in MPIs, considering the facts that there is a lack of descriptive studies on this topic ${ }^{23,48,49}$ and these documents are commonly consulted by the patients and general public. ${ }^{50-52}$ The usability test raised the question about the appropriateness of the tested illustrations and tables for the proper use of medicines, since some interpretation issues were detected in the case of the tested graphic elements.

Study A: Describing, characterising and analysing the graphic elements of MPIs

Although it is widely accepted that the use of visual information in MPIs improves patients' comprehension, memorisation, satisfaction and treatment adherence, ${ }^{11-14,53}$ a relatively small number of illustrations were found in the sampled MPIs. The illustrations were predominantly identified in the MPIs of CNS medicines (e.g. benzodiazepine and antidepressants), which might be due to the therapeutic specificities of these medicines, such as the possibility of dangerous intoxications accompanied by respiratory suppression in case of incorrect use. Other important graphic elements for emphasising and highlighting portions of text (e.g. bold or list/ iterations with bullets) ${ }^{17,23,24,27,33}$ were also were scarcely used in the sampled MPIs. One positive finding of this study was that, in accordance to the international regulations, few non-compliant graphical elements were identified, such as headings with boxes, italics and underline, ${ }^{17,23,24,33}$ although the use of graphic elements in the text of the MPIs is not specifically determined in the Portuguese pharmaceutical regulations. ${ }^{36}$ It is well known that, the use of uppercase in sections titles, bullet points and bold font ${ }^{17,23,24,27,33}$ also contributes to the proper readability and legibility of the MPIs. On the other hand, the use of capitalised letters in the body text, italics or underline promotes the difficulty of word recognition, ${ }^{17,23}$ thus decreasing the intelligibility of the MPIs.

There are several studies on how to optimise the MPIs' design, ${ }^{23,52,54}$ for instance, Pander et al. (Netherlands, 2010) tested the original (154 potential users of medicines) and optimised (164 potential users of medicines) versions of three MPIs (oxazepam, bisoprolol and rosuvastatin). The following procedures were used in the optimisation of the MPIs: the creation of new headings, the development of a clear headings hierarchy with bold and letters of different sizes, the use of bullet information lists and the elimination of some formats from the body text, such as capitals and underline. On average, only $75 \%$ of the topics were located in the original versions, while simple design optimisations led to a $90 \%$ correct location of the information. ${ }^{53}$ Besides, it is not fully demonstrated that the use of lists/iterations is more appropriated than the use of text or tables, ${ }^{55}$ they were widely used in the sampled MPIs. The large use of lists/ iterations confirmed that the selected MPIs were complex documents encompassing a high number of factual information. Lists/iterations were frequently used in section 2 (What you need to know before you $<$ take $\rangle\langle$ use $\rangle$ X) to present information on dosage and adverse reactions. According to the QRD template, ${ }^{32}$ this section comprises very diverse issues, such as information on contraindications, precautions (e.g. pregnant/breastfeeding women), interactions, effects on the ability to drive or to use machines, etc. In addition, the majority of the selected MPIs presented hyphenated lists, in opposition to the use of bullet points as recommended by the readability guideline of EMA. ${ }^{10}$

Overall, it seemed that the criteria used to conceive and approve the sampled MPIs were not homogeneously applied by MAH and medicines authorities, because the graphic elements were dissimilarly used in the MPIs of the three therapeutic groups (SNC, CS, MS), which possibly influenced the safe use of the medicines. This is even more important, knowing that some Portuguese MPIs are direct translations of MPIs available in other European countries (e.g. medicines approved via a centralised procedure). ${ }^{32,40}$ Therefore, future research, specifically on how to use graphic elements in the MPIs is recommended.

Study B: The usability of some illustrations and tables from the sampled MPIs

Besides the fact that a usability proof is required to approve all MPIs of medicinal products for 
human use in Europe,${ }^{10}$ interpretation issues were identified in the case of the tested illustrations, especially in the case of the figures only, thus confirming the difficulty of selecting appropriate illustration to use in the MPIs. Furthermore, databases on validated illustrations to be used in the health information materials are limited, ${ }^{30,31,56}$ such as the illustration database of the United States Pharmacopoeia. ${ }^{56}$ In fact, the of tested and validated illustrations to be used in particular databases for each country is advisable, regarding the cultural and social differences among countries. For instance, only some US pictograms were fully understood by a group of clients of Portuguese pharmacies. ${ }^{30}$

Participants' comprehension of pictograms was better with statistical significance than the comprehension of figures, maybe because pictograms contain more illustrated information and stepwise explanations than figures. Nevertheless, and similarly to previous studies, the participants' comprehension of illustrations with text were significantly better than illustrations alone. ${ }^{11,14,18}$ The placement of supplementary information near the illustrations and not only in the text (e.g. use of subtitles on critical information directly in the pictogram) seems important, because this important information might be skipped in the text and not correctly interpreted in the pictogram. For instance, if the important items of information to "not remove the adapter after the first utilisation" or to "use water as the appropriate liquid to wash the syringe" in the Valproic Acid MPI text (Appendix B) are skipped in the text, it is very likely that the pictogram will not be helpful to avoid the incorrect use of the medicine.

Usability issues were also identified in tables. For instance, the participants' consultation of tables associated with the performance of some simple mathematical operations was not devoid of interpretation issues, even if the participants were of high literacy level. Oppositely, the simpler consultation of tables, i.e. crossing a single row with a single column without the performance of mathematical calculations, was not associated with interpretation issues, which confirms the importance of developing simple and clear tables. Considering that the tables with more rows and columns were probably more complex and difficult to consult, it seems that the tables with simple formats are more suitable to be used in health information material. In this context, it is also advisable that all the tables should be submitted to specific usability tests during their development and approval stages.

Interestingly, the participants were not too demanding in relation to tables' layout and design, classifying on average as good, even if the two evaluated tables presented different graphic characteristics (e.g. number of columns and rows) (Appendix B). Participants' opinion on the layout of these tables was not significantly different, which suggest further studies on the ideal characteristics of tables.

\section{Study strengths}

There are few descriptive studies specifically on the graphic elements of the MPIs, ${ }^{23,48,49}$ and in particular, studies using a large sample of MPIs. Some of the analysed MPIs are also available in other European Countries (e.g. the MPIs of the medicines approved via a centralised procedure), which makes the present results interesting to an international audience. ${ }^{32,47,57}$ Participants with high literacy levels are more likely to understand the visual or written medicine information in comparison to the low-literate patients and to avoid issues expected to be common with the participants of the low educational levels. ${ }^{4,5,8}$ The distribution of age, year course and sex was homogenous between the three groups (illustrations only, illustrations plus text and text only) and similar sample sizes were used in previously published studies. ${ }^{10,11,18,46}$

\section{Study limitations}

Participants with different health conditions and from different cultural backgrounds were not included, and a relatively small number of participants were enrolled in the usability study. In a more realistic approach, the original MPIs and packages of medicines (e.g. syrup bottles or outside packages) should have been used in the usability study, instead of text transcriptions in a questionnaire. The use of original materials was not possible due to logistic reasons. The female 
participants were prevalent in this study, which might have influenced the study results. Triangulation methods to double-check the results were not performed, such as eye-tracking studies. $^{58,59}$

\section{Practical implications}

Overall, it is advisable to validate the graphical content of MPIs, for instance through the formation of standardised illustrations databases. Specific legibility tests to evaluate participants' comprehension of illustrations and tables, or tests to detect other typographic issues in the MPIs, e.g. tests to evaluate the visual perception of words and forms or the appropriateness of the size and type of letters, ${ }^{31}$ are recommended. Besides the specific quantitative and qualitative problems on the MPIs graphical content here identified, this study raises the importance of assuring the appropriateness of the layout and design of all types of written health materials. In this context, health information professions must be aware of these requisites when developing or supervising health related information. Actually, these professionals should be involved in the development of validated graphical health information, for instance contributing to a standardised illustrations databases.

Also, this study increases the interest of practitioners, researchers and students from library and health information on the relevance of MPIs and their graphical content, thus promoting the development of new intervention areas in this sector and contributing to a higher social impact of the health library related sciences. On the other hand, public libraries also may index and classify these type of health documents i.e. consumers medicine information. As a consequence, the general public, and particularly those unable to find precise and reliable drug-related information may benefit from the availability of these documents in libraries.

\section{Conclusions}

Graphic elements that negatively impact the legibility of the MPIs were detected in this study, such as the frequent use of hyphenated lists/ iterations and capitalised letters, and the use of underline and italics in the body text. In addition, illustrations and tables were scarcely used, which might have a negative impact in the legibility of the MPIs. Although the advantage of using graphic elements specifically on "how to use the medicine" is not fully demonstrated, the majority of the graphic elements were related to this topic. It is likely that some of the tested illustrations and tables need to be optimised, since legibility issues were identified in the usability study. A revision of the graphical content of inserts in medicines packages and the update and enforcement of the regulations on the use of illustrations or other graphic elements is needed, including more rigorous legibility tests before the approval of MPIs into the market. Moreover, experts in library and health information should have a more predominant role in the production, supervision and indexing of written health materials, such as MPIs. Therefore, this study highlights the need to carefully review/assess the MPI's design and increase health information experts' awareness in this area.

\section{Acknowledgements}

FCT (Foundation for Science and Technology), iMed.ULisboa (Research Institute for Medicines and Pharmaceutical Sciences, University of Lisbon) and the Phonetic Lab (School of Arts and Humanities, University of Lisbon).

\section{Funding}

Carla Pires is a doctoral student (Fundação para a Ciência e Tecnologia Grant: SFRH/BD/76531/ 2011; Lisbon; Portugal; http://www.fct.pt/ index.phtml.en). This research was partially funded by PEst-OE/LIN/UI0214/2013, FCT, Portugal.

\section{Conflicts of interest}

None.

\section{References}

1 Hirschberg, I., Seidel, G., Strech, D., Bastian, H. \& Dierks, M. L. Evidence-based health information from the users' perspective-a qualitative analysis. BMC Health Services Research, 2013, 10, 13-405.

(C) 2015 Health Libraries Group Health Information \& Libraries Journal, 33, pp. 121-139 
2 Whitney, W., Dutcher, G. A. \& Keselman, A. Evaluation of health information outreach: theory, practice, and future direction. Journal of the Medical Library Association: JMLA, 2013, 101, 138-146.

3 Jackson, R., Baird, W., Davis-Reynolds, L., Smith, C., Blackburn, S. \& Allsebrook, J. Qualitative analysis of parents' information needs and psychosocial experiences when supporting children with health care needs. Health Information and Libraries Journal, 2008, 25, 31-37.

4 Berkman, N. D., Sheridan, S. L., Donahue, K. E., Halpern, D. J. \& Crotty, K. Low health literacy and health outcomes: an updated systematic review. Annals of internal medicine, 2011, 155, 97-107.

5 Bostock, S. \& Steptoe, A. Association between low functional health literacy and mortality in older adults: longitudinal cohort study. BMJ: British Medical Journal / British Medical Association, 2012, 15, 344.

6 Hamrosi, K. K., Raynor, D. K. \& Aslani, P. Enhancing provision of written medicine information in Australia: pharmacist, general practitioner and consumer perceptions of the barriers and facilitators. BMC Health Services Research, 2014, 14, 183.

7 Edwards, B. \& Chakraborty, S. Risk Communication and the Pharmaceutical Industry: what is the reality? Drug safety, 2012, 1, 35.

8 LeBrun, M., DiMuzio, J., Beauchamp, B., Reid, S. \& Hogan, V. Evaluating the health literacy burden of Canada's public advisories: a comparative effectiveness study on clarity and readability. Drug Safefty, 2013, 36, 1179-1187.

9 European Parliament. (2001). Directive 2001/83/EC: Community code relating to medicinal products for human use. Title V: Labelling and package leaflet. Available at http://eur-lex. europa.eu/LexUriServ/LexUriServ.do?uri=OJ:L:2001:311:00 67:0128:en:PDF. Accessed on July 24, 2015.

10 European Commission. (2009). Guideline on the readability of the labelling and package Leaflet of medicinal products for human use. Available at http://ec.europa.eu/health/files/ eudralex/vol-2/c/2009_01_12_readability_guideline_final_en. pdf. Accessed on June 3, 2014.

11 Katz, M., Kripalani, S. \& Weiss, B. Use of pictorial aids in medication instructions: a review of the literature. American Journal of Health-System Pharmacy, 2006, 63, 2391-2397.

12 Houts, P. S., Doak, C. C., Doak, L. G. \& Loscalzo, M. J. The role of pictures in improving health communication: a review of research on attention, comprehension, recall, and adherence. Patient Education and Counseling, 2006, 61, 173-190.

13 Kripalani, S., Robertson, R., Love-Ghaffari, M. H., Henderson, L. E., Praska, J., Strawder, A., Katz, M. G. \& Jacobson, T. A. Development of an illustrated medication schedule as a low-literacy patient education tool. Patient education and counseling, 2007, 66, 368-377.

14 Houts, P. S., Witmer, J. T., Egeth, H. E., Loscalzo, M. J. \& Zabora, J. R. Using pictographs to enhance recall of spoken medical instructions II. Patient Education and Counseling, 2001, 43, 231-242.

15 Food and Drug Administration. (2003). Requirements for Submission of Labeling for Human Prescription Drugs and
Biologics in Electronic Format. Available at http://www.gpo. gov/fdsys/pkg/FR-2003-12-11/pdf/03-30641.pdf. Accessed on June 3, 2014.

16 Therapeutic Goods Administration. (2008). Best practice guideline on prescription medicine labelling. Available at http://www.tga.gov.au/industry/labelling-pm-best-practice.htm. Accessed on June 15, 2014.

17 European Medicine Agency. (2011a). QRD convention to be followed for the EMA-QRD templates. Patient Health Protection. Available at http://www.emea.europa.eu/docs/en_GB/ document_library/Regulatory_and_procedural_guideline/2009/ 10/WC500005091.pdf. Accessed on July 13, 2014.

18 Morrow, D. G., Hier, C. M., Menard, W. E. \& Leirer, V. O. Icons improve older and younger adults' comprehension of medication information. The Journals of Gerontology. Series B, Psychological Sciences and Social Sciences, 1998, 53, P240-P254.

19 Mansoor, L. E. \& Dowse, R. Effect of Pictograms on readability of patient information materials. Annals of Pharmacotherapy, 2003, 37, 1003-1009.

20 Sojourner, R. J. \& Wogalter, M. S. The influence of pictorials on the comprehension and recall of pharmaceutical safety and warning information. International Journal of Cognitive Ergonomics, 1998, 2, 93-106.

21 Webb, J., Davis, T. C., Bernadella, P., Clayman, M. L., Parker, R. M., Adler, D. \& Wolf, M. S. Patient-centered approach for improving prescription drug warning labels. Patient Education and Counseling, 2008, 72, 443-449.

22 Wallace, L. S., Roskos, S. E. \& Weiss, B. D. Readability characteristics of consumer medication information for asthma inhalation devices. Journal of Asthma, 2006, 43, 375-378.

23 Tong, V., Raynor, D. K. \& Aslani, P. Design and comprehensibility of over-the-counter product labels and leaflets: a narrative review. International Journal of Clinical Pharmacy, 2014a, 36, 865-872.

24 Aldridge, M. D. Writing and designing readable patient education materials. Nephrology Nursing Journal: Journal of the American Nephrology Nurses' Association, 2004, 31, 373-377.

25 The Pharmacy Guild of Australia. (2007). Investigating Consumer Medicine Information (I-CMI) Project. 36-39, 191-253. Available at http://guild.org.au/docs/default-source/publicdocuments/services-and-programs/research-and-development/ Fourth-Agreement-R-and-D/Investigating-Consumer-Medicine-Information-(I-CMI)-Project/full-final-report-part-1.pdf? sfvrsn=0. Accessed on December 11, 2014.

26 Vromans, L., Doyle, G., Petak-Opel, S., Rödiger, A., Röttgermann, M., Schlüssel, E. \& Stetter, E. Shaping medicinal product information: a before and after study exploring physicians' perspectives on the summary of product characteristics. BMJ Open, 2013, 21, 3.

27 Gilliland, J. (1972). Readability: A UKRA Teaching of Reading Monograph. London: University of London Press.

28 Kools, M., van de Wiel, M. W., Ruiter, R. A. \& Kok, G. Figures and text in instructions for medical devices: effects on recall and actual performance. Patient Education and Counseling, 2006, 64, 104-111. 
29 Garcia-Retamero, R., Okan, Y. \& Cokely, E. T. Using visual aids to improve communication of risks about health: a review. The ScientificWorld Journal, 2012, 2012, 562637.

30 Soares, M. A. Legibility of USP pictograms by clients of community pharmacies in Portugal. International Journal of Pharmacy Practice, 2013, 35, 22-29.

31 Bui, D., Nakamura, C., Bray, B. E. \& Zeng-Treitler, Q. Automated Illustration of Patients Instructions. American Medical Informatics Association Annual Symposium Proceedings, 2012, 2012, 1158-1167.

32 European Medicine Agency. (2015a). Product Information: Quality Review of Documents human product-information annotated template. Available at http://www.ema.europa. eu/ema/index.jsp?curl=pages/regulation/document_listing/ document_listing_000134.jsp. Accessed on July 24, 2015.

33 European Medicine Agency. (2011b). QRD recommendations on package design and labelling for centrally authorized non-prescription human medicinal products (Draft). Available at http://www.ema.europa.eu/docs/en_GB/document_library/Regulatory_and_procedural_guideline/2011/04/ WC500104662.pdf. Accessed on July 13, 2014.

34 Infarmed. (2013). National prescribing guide. Health Ministry; December 2012. Available at http://www.infarmed.pt/portal/pls/portal/!PORTAL.wwpob_page.show?_docname $=8944263$. PDF. Accessed on June 21, 2014.

35 Infarmed. (2011). Medicine Statistic 2011: Distribution of NHS Medicines Sales and Average Cost per Package by therapeutic Groups and Subgroups; 2012. Available at http://www.infarmed.pt/portal/page/portal/INFARMED/PUBLICACOES/TEMATICOS/ESTATISTICA_MEDICAMENTO. Accessed on May 6, 2014.

36 Infarmed. (2006). Law Decree N. ${ }^{\circ}$ 176/2006: Medicine Law (Estatuto do Medicamento). Available at http://www.infarmed.pt/portal/page/portal/INFARMED/LEGISLACAO/ LEGISLACAO_FARMACEUTICA_COMPILADA/TITULO_III/TITULO_III_CAPITULO_I/035-E_DL_176_2006_9ALT. pdf. Accessed on July 23, 2015.

37 Infarmed. (2012). Data base: Infomed (Informação sobre medicamentos do INFARMED). Available at www.infarmed.pt/infomed/inicio.php. Accessed on June 21, 2014.

38 The American Heritage dictionary of the English Language. (2013). Pictograph definition. Available at http://www.ahdictionary.com/word/search.html?id=P5317200. Accessed on January 11, 2014.

39 Fuchs, J., Scheunpflug, C. \& Götze, E. The influence of the European Union's QRD template on the use of package inserts compared with a shorter model template. Die Pharmazeutische Industrie, 2012, 74, 126-136.

40 European Medicine Agency. (2015b). Central authorisation of medicines. Available at http://www.ema.europa.eu/ema/index. jsp?curl=pages/about_us/general/general_content_000109.jsp. Accessed on July 27, 2015.

41 Brazilian Association of technical rules. (1985). NBR 5425: Inspection by attributes. Available at http://pt.scribd.com/doc/58002631/NBR-5425-Guia-Para-Inspecao-Por-emNo-Controle-E-Certificacao-de-Qualidade\#scribd. Accessed on July, 252015.
42 Kim, H., Nakamura, C. \& Zeng-Treitler, Q. Assessment of pictographs developed through a participatory design process using an online survey tool. Journal of Medical Internet Research, 2009, 11, e5.

43 Al-Ramahi, R., Zaid, A. N., Kettana, N., Sweileh, W. \& Al-Jabi, D. Attitudes of consumers and healthcare professionals towards the patient package inserts - a study in Palestine. Pharmacy Practice (Granada), 2012, 10, 57-63.

44 National statistical Institute. (2011). Census results 2011. Available at http://censos.ine.pt/xportal/xmain?xpid=CENSOS\&xpgid= ine_censos_publicacao_det\&contexto=pu\&PUBLICACOESpub_ boui $=73212469 \&$ PUBLICACOESmodo=2\&selTab=tab $1 \& p c e n$ sos $=61969554$. Accessed on December 11, 2014.

45 Escola Nacional de Saúde Publica. (2014). Preliminary results: European questionnaire in health literacy (HLS-EUPT). Available at http://www.saudequeconta.org/index.php/ site/literacia\#apresentacao_dos_resultados. Accessed on December 11, 2014

46 Dickinson, D., Raynor, D. K. \& Duman, M. Patient information leaflets for medicines: using consumer testing to determine the most effective design. Patient education and counseling, 2001, 43, 147-159.

47 European pharmaceutical market research association. (2013). New form code classification guidelines. 10-11. Available at http://www.ephmra.org/user_uploads/nfcversion2013guidelines(1).pdf. Accessed on December 11, 2014.

48 Twomey, C. An analysis of patient information leaflets supplied with medicines sold by pharmacists in the United Kingdom. Library and Information Research News, 2001, 25, 3-12.

49 Sansgiry, S. S. \& Shringarpure, G. Manufacturers' compliance with the US Food and Drug Administration's over-thecounter human drugs: labeling requirements. Packaging Technology and Science, 2003, 16, 91-98.

50 Nathan, J. P., Zerilli, T., Cicero, L. A. \& Rosenberg, J. M. Patients' use and perception of medication information leaflets. Annals of Pharmacotherapy, 2007, 41, 777-782.

51 Tong, V., Raynor, D. K., Blalock, S. J. \& Aslani, P. Exploring consumer opinions on the presentation of side-effects information in Australian Consumer Medicine Information leaflets. Health Expectations: An International Journal of Public Participation in Health Care and Health Policy, 2014b, doi: 10.1111/hex.12215.

52 Vander Stichele, R. H., Van Haecht, C. H., Braem, M. D. \& Bogaert, M. G. Attitude of the public toward technical package inserts for medication information in Belgium. Drug Interaction and Clinical Pharmacy, 1991, 25, 10021006.

53 Pander, M. H. \& Lentz, L. Improving the usability of patient information leaflets. Patient Education and Counseling, 2010, 80, 113-119.

54 David, S. Designing public documents. Information Design Journal, 2004, 12, 24-35.

55 Vancheri, C. (2010). The Safe Use Initiative and Health Literacy: Workshop Summary. The National Academies Press: Washington; Available at http://books.nap.edu/openbook.php? record_id=12975\&page=R1. Accessed on January 11, 2014. 
56 United States Pharmacopeial convention. (1997). USP Pictograms Library. Available at http://www.usp.org/usp-healthcare-professionals/related-topics-resources/usp-pictograms. Accessed on July 24, 2015.

57 Haw, C. \& Stubbs, J. Patient information leaflets for antidepressants: are patients getting the information they need? Journal of Affective Disorders, 2011, 128, 165-170.

58 Ashby, J., Rayner, K. \& Clifton, C. Eye movements of highly skilled and average readers: differential effects of fre- quency and predictability. Quarterly Journal of Experimental Psychology, 2005, 58, 1065-1086.

59 Orquin, J. L. \& Mueller, L. T. Attention and choice: a review on eye movements in decision making. Acta Psychologica, 2013, 144, 190-206.

Received 11 January 2015; Accepted 19 October 2015

\section{Appendix A}

Checklist

\begin{tabular}{|c|c|c|}
\hline & Graphic elements & Response options \\
\hline \multirow[t]{16}{*}{1.} & Figures: & \\
\hline & Figures presence? & No or Yes \\
\hline & In case of Figures presence: & \\
\hline & Number of Figures & 1 - None figure \\
\hline & & 2 - One figure \\
\hline & & 3 - Two figures \\
\hline & Figures location? (by section) & MPI section 1-6: \\
\hline & & 1. What is $X(X=$ medicinal product name $)$ and what is used for; \\
\hline & & 2. What you need to know before you $<$ take $><$ use $>$ X; \\
\hline & & 3. How to $<$ take $><$ use $>$ X; \\
\hline & & 4. Possible side effects; \\
\hline & & 5. How to store $X_{i}$ \\
\hline & & 6. Contents of the package and other information. \\
\hline & Figures classification & $1-$ How to $<$ take $><$ use $>$ \\
\hline & (according Qualitative descriptors) & 2 - How it looks like \\
\hline & & 3 - Precautions \\
\hline \multirow[t]{7}{*}{2.} & Pictograms: $^{a}$ & \\
\hline & $\begin{array}{l}\text { Pictograms presence? } \\
\text { In case of Pictograms presence: }\end{array}$ & No or Yes \\
\hline & Number of Pictograms & 1 - None pictogram \\
\hline & & 2 - One pictogram \\
\hline & & 3 - Two pictograms \\
\hline & Pictograms location? (by section) & MPI section 1-6 \\
\hline & $\begin{array}{l}\text { Pictograms classification } \\
\text { (according Qualitative descriptors) }\end{array}$ & $1-$ How to $<$ take $><$ use $>$ \\
\hline \multirow[t]{14}{*}{3.} & Tables: & \\
\hline & Tables presence? & No or Yes \\
\hline & In case of Tables presence: & \\
\hline & Number of Tables & 1 - None table \\
\hline & & 2 - One table \\
\hline & & 3 - Two tables \\
\hline & Tables location? (by section) & MPI section 1-6 \\
\hline & Tables classification & 1 - ADR description and frequency \\
\hline & (according Qualitative descriptors) & 2 - ADR frequency \\
\hline & & 3 - Precautions \\
\hline & & 4 - Interactions \\
\hline & & 5 - Posology \\
\hline & & 6 - Fargerström Test \\
\hline & & 7 - Marketing Authorization Holders \\
\hline
\end{tabular}

(continued) 
Appendix A. (continued)

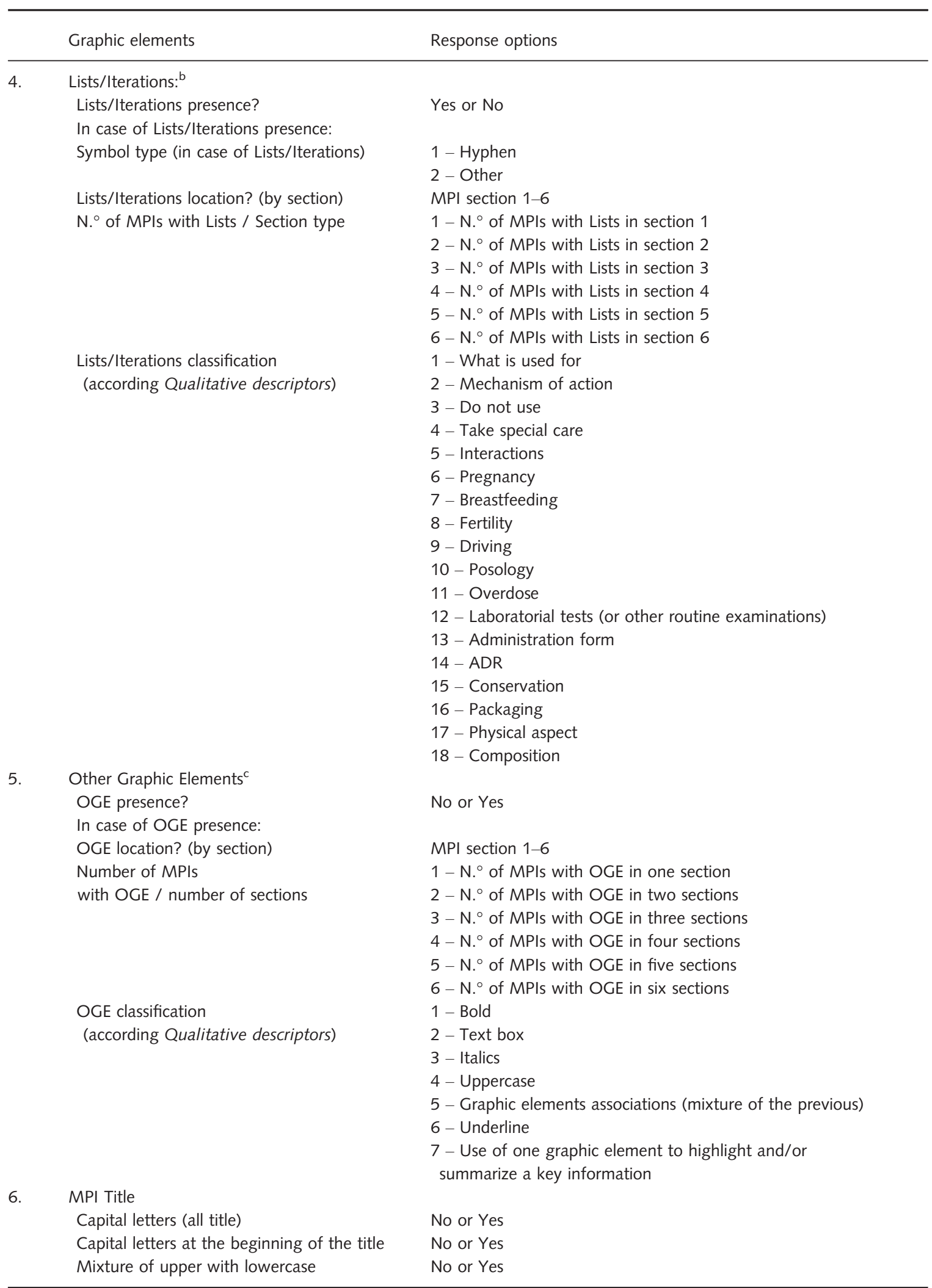

${ }^{a} \mathrm{OGE}$, other graphic elements; $\mathrm{MPI}$, medicine package insert; ADR, adverse drug reactions. 
apictogram: a pictorial representation formed at least for two figures.

${ }^{b}$ Lists/Iterations: lists of words preceded by hyphens, bullets points or other, e.g. lists of adverse reaction.

'OGE: bold font, italics, underline, capitalized letters in the body text, headings with text boxes, associations of the previous graphic elements, other graphic elements used to highlight information, and the case format of the section titles (uppercase, lowercase or both).

Appendix B

Questions, illustrations and tables used in the usability test

Figure 3 is available Infomed ${ }^{37}$ on-line in a Mirtazepine medicine package insert (MPI).

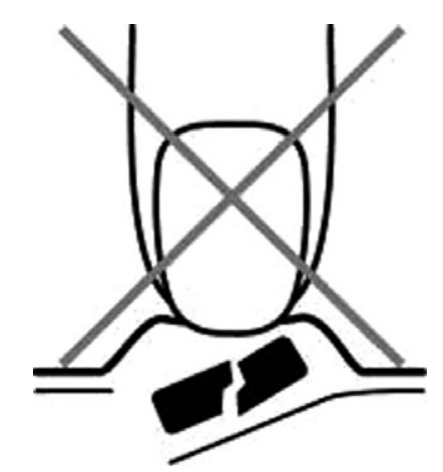

Figure 3 Do not break the tablet

Question: Knowing that a tablet is represented in the figure, please give (in few words) your personal opinion about the interpretation of the figure

Figure 4 is available on-line Infomed ${ }^{37}$ in an Escitalopram MPI.

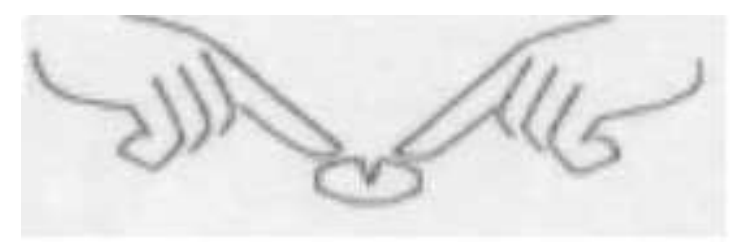

Figure 4 How to split the pill

Question: Knowing that a pill is represented in the figure, please give (in few words) your personal opinion about the interpretation of the figure 
Figure 5 is available on-line Infomed ${ }^{37}$ in a Valproic acid MPI.
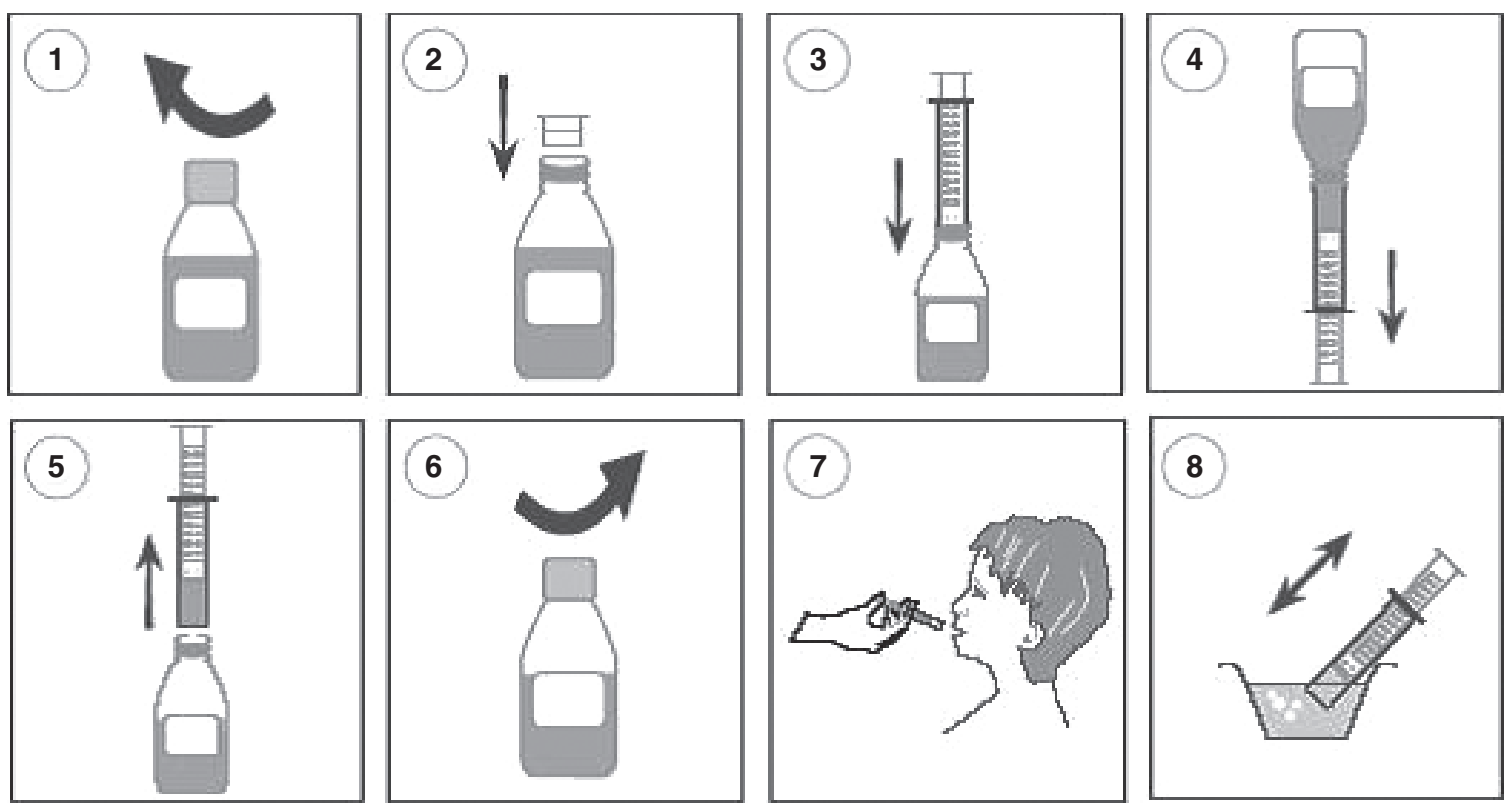

Figure 5 Pictogram: syrup administration

Question: Knowing that the administration of syrup is represented in the illustration; please give (in few words) your personal opinion about the interpretation of each one of the 8 figures

Figure 6 is available on-line Infomed ${ }^{37}$ in a Diclofenac MPI.
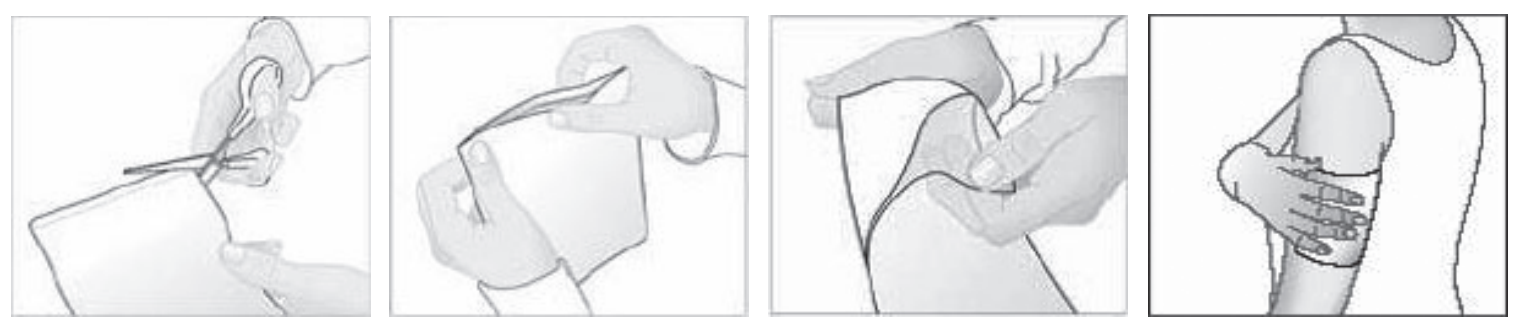

Figure 6 Pictogram: Transdermal system application (Step 1 of 4)

Question: Knowing that a transdermal patch is represented in the illustration, please give (in few words) your personal opinion about the interpretation of each one of the 4 figures

Table B.1 Oral suspension dosage instructions.

\begin{tabular}{ll}
\hline Age and body weight & Dosage \\
\hline Children from 3-6 months (body weight of about 5-7.6 kg) & May be taken a dose of 2.5 ml, 3 times in 24 hours \\
Children from 6-12 months (body weight of about 7.7-9 kg) & May be taken a dose of 2.5 ml, 3-4 times in 24 hours \\
Children from 1-3 years (body weight of about 10-15 kg) & May be taken a dose of 5 ml, 3 times in 24 hours \\
Children from 4-6 years (body weight of about 16-20 kg) & May be taken a dose of 7.5 ml (5 ml + 2.5 ml), \\
& $\begin{array}{c}3 \text { times in 24 hours } \\
\text { Children from 7-9 years (body weight of about 21-29 kg) }\end{array}$ \\
Children from 10-12 years (body weight of about 30-40 kg) & May be taken three doses of 5 ml, 3 times in 24 hours \\
\hline
\end{tabular}

A Portuguese version of Table B.1 is available on-line Infomed ${ }^{5}$ in an Ibuprofen MPI. 
Table B.2 Syrup dosage instructions.

\begin{tabular}{lllll}
\hline Age & Body Weight & $\begin{array}{l}\text { Dosage of Paracetamol } \\
\text { for each administration }\end{array}$ & $\begin{array}{l}\text { Volume of Paracetamol } \\
\text { for each administration }\end{array}$ & $\begin{array}{l}\text { Maximum Dose of } \\
\text { Paracetamol in 24 hours }\end{array}$ \\
\hline $3-6$ months & Up to $7 \mathrm{~kg}$ & $70-100 \mathrm{mg}$ & $1.75-2.5 \mathrm{ml}$ & $350 \mathrm{mg}$ \\
7 months to 1 year & $8-10 \mathrm{~kg}$ & $100-150 \mathrm{mg}$ & $2.5-3.75 \mathrm{ml}$ & $500 \mathrm{mg}$ \\
$2-3$ years & $11-15 \mathrm{~kg}$ & $150-200 \mathrm{mg}$ & $3.75-5 \mathrm{ml}$ & $750 \mathrm{mg}$ \\
$4-6$ years & $16-22 \mathrm{~kg}$ & $200-300 \mathrm{mg}$ & $5-7.5 \mathrm{ml}$ & $1000 \mathrm{mg}$ \\
$7-9$ years & $23-30 \mathrm{~kg}$ & $300-500 \mathrm{mg}$ & $7.5-12.5 \mathrm{ml}$ & $1500 \mathrm{mg}$ \\
$10-12$ years & $31-40 \mathrm{~kg}$ & $400-600 \mathrm{mg}$ & $10-15 \mathrm{ml}$ & $2000 \mathrm{mg}$ \\
More than 12 years & More than 41 kg & $500-1000 \mathrm{mg}$ & $12.5-25 \mathrm{ml}$ & $3000 \mathrm{mg}$ \\
\hline
\end{tabular}

A Portuguese version of Table B.2 is available on-line Infomed ${ }^{5}$ in a Paracetamol MPI.

\section{Questions:}

a) Rate the tables in relation to its general appearance (organization of the information in the table and layout). Mark with a cross the answer that you consider more adequate.

\begin{tabular}{lc}
\hline Very Good & $\square$ \\
Good & $\square$ \\
Medium & $\square$ \\
Bad & $\square$ \\
Very Bad & $\square$ \\
\hline
\end{tabular}

Table B.2:

\begin{tabular}{lc}
\hline Very Good & $\square$ \\
Good & $\square$ \\
Medium & $\square$ \\
Bad & $\square$ \\
Very Bad & $\square$ \\
\hline
\end{tabular}

b) Please consult Table B.2. How many syrup is needed to a children with 8 years old and $25 \mathrm{~kg}$ (in a single administration)? Please answer giving the exact volume (not respond within a volume range). 